\title{
Das buckelige Profil
}

Liebe Leserinnen, liebe Leser,

für die Welt meiner Großväter habe ich noch ein Gespür - wenn auch ein schwaches -, habe ich ja beide noch gekannt. Wollte ich aber das Gespür meinen Kindern oder gar Enkeln vermitteln, wüsste ich nicht wie. Ich könnte nur sagen: Die Welt vor hundert Jahren war anders als die heutige; nicht nur äußerlich. Die Menschen lebten, dachten und verstanden sich anders. Für meinen Großvater mütterlicherseits war das damals aufkommende Telefon nicht christlich legitimiert. Er argwöhnte wohl, dass der Teufel dahinter stecken könnte. Wurde er gefragt, wie es funktioniere, dann sagte er - mehr aus Verlegenheit - da seien Drähte zwischen hier und dort. Die seien hohl wie dünne Röhren. Durch die Röhren hindurch könne man sich unterhalten. Das reichte für sein Verständnis der Welt. Er verstand sie nicht naturwissenschaftlich; sondern als von Gott unerklärbar regiert. Das war kaum anders als im Mittelalter. Nun hat es sich geändert. Drei Generationen später haben wir Naturwissenschaft und Technik verinnerlicht. Wir können uns die Welt nicht ohne sie vorstellen. Jeder Empathieversuch scheitert daran, dass wir nicht zur Einfalt des Nichtwissens finden können. Über je mehr Generationen man in diesem Zuge in der Geschichte zurückdenkt, umso weniger können wir uns in die damals lebenden Menschen versetzen. Wir können zwar das, was Goethe geschrieben hat, auch heute lesen und irgendwie empfinden; wie sich aber Goethe dabei ungeschrieben vorkam, wissen wir nicht; wenn auch spätere Literaturkritiker dazu unterschiedliche reizvolle Interpretationen ${ }^{1}$ haben. Wie sich gar Goethes anonymer Schuhmacher zur Welt stellte, bleibt uns im Dunklen. Das ist das Unbefriedigende an der Beschäftigung mit der Geschichte: Man kann sich zu den historischen Fakten alles menschlich Mögliche vorstellen, kaum aber das Richtige. Sollte man zufällig richtig liegen, kann man es nicht wissen.

Weil ich in meinem Ausgedinge mit dem praktischen Datenschutz kaum noch zu tun habe und mir so seine aktuelle Fülle entgeht, mache ich mir Gedanken über seine historischen Wurzeln. Das ist schwierig, denn vor kurzem war er noch unbekannt. Trotzdem glaube ich, dass sich in fünftausend Jahren überblickbarer Geschichte einiges finden lässt, das auf den Datenschutz hinführt. Ich habe mich in der Kolumne 08/09 mit der historischen Esoterik befasst. Sie wollte - wie der Datenschutz - Information vor Proliferation schützen. Aber diese Information war gruppen- und nicht personenbezogen. Die Menschen empfanden sich als unveränderlich ihrer Gruppe zugehörig. Die mittelalterlichen Bilder des jüngsten Gerichts zeigen z.B. die Auferstehenden gruppenweise dem thronenden Christus zu Füßen, auf der einen Seite die Seligen, auf der anderen die Verdammten; unter den Verdammten die Wucherer, die Schlemmer, der verderbte Teil der Geistlichkeit etc., je nachdem kollektiv bestraft oder geschont. Mit der Zeit kam eine andere Sichtweise auf. Den Menschen wurde von den Theologen gesagt, dass sie nicht auf das Jüngste Gericht zu warten haben, sondern unmittelbar nach dem Tode für ihre persönlichen Taten gerichtet würden, ohne die Möglichkeit, sich im Kollektiv zu verbergen. Zu jedem Menschen werde über seine persönlichen guten und bösen Taten im Himmel Buch geführt. Der Prozentsatz der zur Verdammnis anstehenden wurde von den Theologen sehr hoch angesetzt. Jeder Mensch bangte um seine persönliche ewige Seligkeit und wurde damit von seinem Beichtiger diszipliniert. Ihn quälte die Furcht vor einem strengen Richter, der ihm einst sein detailliertes buckliges Persönlichkeitsprofil unerbittlich aufblättert.

Also, liebe Leserinnen und Leser, ist die Angst vor Datensammlungen nichts Neues. Sie steht bezeichnender Weise am Anfang unserer kollektiven Hinwendung zur Person.

Mit freundlichen Grüßen, Ihr

\section{Kail Rhavels}

1 Goethe sagte im Gespräch mit Eckermann, Lily Schönemann sei seine erste und letzte Liebe gewesen. Der Philologe Heinrich Düntzer soll das mit „Hier irrt Goethe“ kommentiert haben. 